\title{
REVISED Behavioural evidence for self-medication in
}

\section{bumblebees? [version 3; peer review: 3 approved]}

Previously titled: Weak and contradictory effects of self-medication with nectar nicotine by parasitized bumblebees

\section{David Baracchi ${ }^{1}$, Mark J. F. Brown², Lars Chittka1}

${ }^{1}$ Department of Biological and Experimental Psychology, School of Biological and Chemical Sciences, Queen Mary University of London, Mile End Road, London, E1 4NS, UK

${ }^{2}$ School of Biological Sciences, Royal Holloway University of London, Egham, Surrey, TW20 0EX, UK

V3 First published: 19 Mar 2015, 4:73

https://doi.org/10.12688/f1000research.6262.1

Second version: 26 May 2015, 4:73

https://doi.org/10.12688/f1000research.6262.2

Latest published: 29 Oct 2015, 4:73

https://doi.org/10.12688/f1000research.6262.3

\section{Abstract}

The presence of antimicrobial secondary metabolites in nectar suggests that pollinators, which are threatened globally by emergent disease, may benefit from the consumption of nectars rich in these metabolites. We tested whether nicotine, a nectar secondary metabolite common in Solanaceae and Tilia species, is used by parasitized bumblebees as a source of self-medication, using a series of toxicological, microbiological and behavioural experiments. Caged bees infected with Crithidia bombi had a slight preference for sucrose solution laced with the alkaloid and behavioural tests showed that the parasite infection induced an increased consumption of nicotine during foraging activity, though nicotine had an appetite-reducing effect overall. When ingested, nicotine delayed the progression of a gut infection in bumblebees by a few days, but dietary nicotine did not clear the infection, and after 10 days the parasite load approached that of control bees. Moreover, when pathogens were exposed to the alkaloid prior to host ingestion, the protozoan's viability was not directly affected, suggesting that anti-parasite effects were relatively weak. Nicotine consumption in a single dose did not impose any cost even in starved bees but the alkaloid had detrimental effects on healthy bees if consistently consumed for weeks. These toxic effects disappeared in infected bees, suggesting that detoxification costs might have been counterbalanced by the advantages in slowing the progression of the infection. Nicotine consumption did not affect bee lifespan but the reduction in the parasite load may have other likely unexplored subtle benefits both for individual bees and their colony. Potential evidence for self-medication is discussed. The contention that secondary metabolites in nectar may be under selection from pollinators, or used by plants to enhance their own reproductive

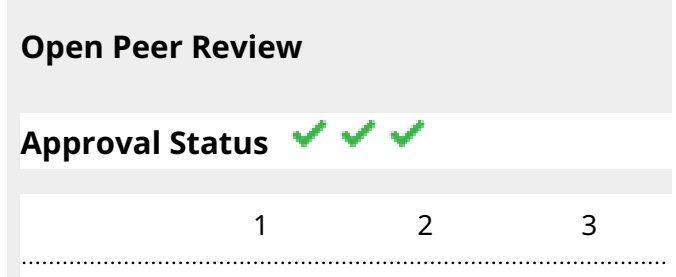

version 3

(revision)

29 Oct 2015

version 2

(revision)

26 May 2015

version 1

19 Mar 2015
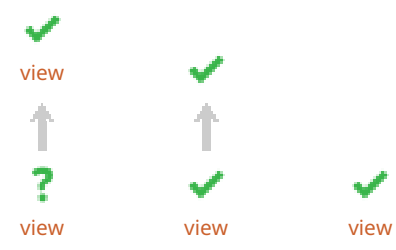

1. James D. Thomson, University of Toronto, Toronto, Canada

2. Michael Simone-Finstrom, North Carolina State University, Raleigh, USA

3. Marla Spivak, University of Minnesota, St Paul, USA

Any reports and responses or comments on the article can be found at the end of the article. 
success, remains to be confirmed.

Keywords

Bombus terrestris, Crithidia bombi, foraging, nicotine, pathogens, pollinators, pollinator-plant interactions, secondary metabolites

This article is included in the Agriculture, Food

and Nutrition gateway.

Corresponding authors: David Baracchi (david.baracchi@gmail.com), MarkJ. F. Brown (Mark.Brown@rhul.ac.uk), Lars Chittka (

l.chittka@qmul.ac.uk)

Competing interests: No competing interests were disclosed.

Grant information: D.B. was supported by a Marie Curie Intra European Fellowship within the 7th European Community Framework Programme.

The funders had no role in study design, data collection and analysis, decision to publish, or preparation of the manuscript.

Copyright: ( $\subset 2015$ Baracchi $D$ et al. This is an open access article distributed under the terms of the Creative Commons Attribution License, which permits unrestricted use, distribution, and reproduction in any medium, provided the original work is properly cited. Data associated with the article are available under the terms of the Creative Commons Zero "No rights reserved" data waiver (CC0 1.0 Public domain dedication).

How to cite this article: Baracchi D, Brown MJF and Chittka L. Behavioural evidence for self-medication in bumblebees? [version 3; peer review: 3 approved] F1000Research 2015, 4:73 https://doi.org/10.12688/f1000research.6262.3

First published: 19 Mar 2015, 4:73 https://doi.org/10.12688/f1000research.6262.1 


\section{REVISED Amendments from Version 2}

We have included additional details regarding the nicotine used in this study including its chirality.

See referee reports

\section{Introduction}

Parasites can have a dramatic impact on their hosts, and consequently provide a powerful selective force for host defence mechanisms. Molecular mechanisms (e.g. the innate and adaptive immune system) are traditionally considered the major anti-parasite defences in the animal kingdom. However, hosts can rely on a range of alternative defence mechanisms, such as morphological barriers (St Leger, 1991), changes in life-history traits (Michalakis, 2009), symbiontmediated defences (Oliver et al., 2010) and altered behaviours (de Roode \& Lefèvre, 2012; Moore, 2002).

Behavioural immunity is an important modality of defence against diseases (de Roode \& Lefèvre, 2012), and medication behaviour is a key immune mechanism in some animals (Clayton \& Wolfe, 1993; de Roode et al., 2013). Medication behaviour has been defined as the selective use of anti-pathogenic substances by infected individuals (Lozano, 1998; Singer et al., 2009), with a measurable benefit to host fitness and negative effects on the pathogen (Abbott, 2014; Clayton \& Wolfe, 1993; Singer et al., 2009). As an additional criterion to support the notion that the substance is only of value as medication, it has been proposed that healthy individuals must suffer a cost when consuming it (Abbott, 2014).

Evidence for self-medication in animals comes from the consumption of curative plants by vertebrates (Rodriguez \& Wrangham, 1993). Many plants contain metabolites that display a wide range of biological activities (Cowan, 1999) which were originally evolved to combat herbivores or plant-parasites (Hadacek, 2002). Chimpanzees, Pan troglodytes, modify their diet to include particular plant species containing medicinal substances to cure helminth infections (Mooney \& Agrawal, 2008; Wrangham, 1995). There are also experimental explorations of self-medication in insects, for example two species of woolly bear caterpillars, which increase their preference for pyrrolizidine alkaloids or iridoid glycosides when parasitized, improving their chances of surviving parasitoid infection (Bernays \& Singer, 2005; Singer et al., 2009; Smilanich et al., 2011). Similarly, fruit fly larvae infected by parasitoid wasp larvae preferentially consumed high-ethanol fly food as a medicine, again increasing their survival (Milan et al., 2012), while no evidence for self-medication to nematode parasitism has been found in the fly Drosophila putrida (Debban \& Dyer, 2013). Trans-generational medication, but not self-medication, has been described in the monarch butterfly (Lefevre et al., 2010) and self-medication has been hypothesized for honeybees that increase plant resin collection in response to a fungal infection (Simone-Finstrom \& Spivak, 2012). Finally, ants apply antimicrobial venomous secretion to the cuticle of contaminated larvae to medicate their brood (Tragust et al., 2013).
Animal societies arguably face intense pressure from pathogens, because of the high number of individuals living in high densities, relatively low genetic variability, and the relatively constant, high levels of humidity and warm temperatures within their nests (Schmid-Hempel, 1998). In addition, social pollinators, such as bumblebees and honeybees, are often exposed to an increased risk of infection via flowers (reviewed in McArt et al., 2014), which represent a shared "public place" where homo- and hetero-colonial conspecifics and other heterospecific pollinators feed repeatedly every day. Given the potential importance of parasites and disease in driving declines of managed honeybees (de Miranda \& Genersch, 2010; Rosenkranz et al., 2010) and wild bumblebees (Cameron et al., 2011; Fürst et al., 2014; Schmid-Hempel et al., 2014; McMahon et al., 2015), understanding the potential relevance of pharmacophagy to social pollinators may be a key to understanding and managing these declines.

Here we use an important natural and managed pollinator, the bumblebee Bombus terrestris, and its parasite Crithidia bombi to investigate the potential for pharmacophagy in social pollinators. C. bombi, a trypanosome gut parasite, is the most prevalent parasite of bumblebees (Shykoff \& Schmid-Hempel, 1991). The parasite, transmitted either vertically or horizontally (Durrer \& SchmidHempel, 1994; Otterstatter \& Thomson, 2007), infects adults per $o s$, and two-three days post infection, infective cells are released through the faeces of bees (Schmid-Hempel \& Schmid-Hempel, 1993). Queens infected by C. bombi have a reduced success in colony founding (Brown et al., 2003), and produce fewer reproductive offspring (Brown et al., 2003), while infected workers experience a higher mortality rate under stressful conditions (Brown et al., 2000). Moreover, infection impairs foraging success and learning abilities, inducing additional costs to the colony (Alghamdi et al., 2008; Gegear et al., 2006). Recent research (Manson et al., 2010; Richardson et al., 2015) has shown that several secondary metabolites such as alkaloids (including nicotine) and glycosides, reduce the $C$. bombi load after consumption by the bumblebee species Bombus impatiens, suggesting that these pollinators might exploit nectar toxins or other metabolites to self-medicate.

To test whether bumblebees are able to self-medicate using naturally occurring nectar secondary metabolites we conducted a series of toxicological, microbiological and behavioural experiments using a different species of Bombus (B. terrestris) and C. bombi as models and nicotine as a natural nectar alkaloid. Nicotine is encountered by pollinators at variable concentrations between $0.1 \mathrm{ng} / \mu \mathrm{l}$ and $3 \mathrm{ng} / \mu \mathrm{l}$ in floral nectar of Nicotiana species (native of South America and naturalised worldwide by humans) and Tilia species (native in most of the temperate Northern Hemisphere) (Detzel \& Wink, 1993; Naef et al., 2004; Tadmor-Melamed et al., 2004).

\section{Methods}

Insects, pathogens and compounds

All experiments were performed with worker bumblebees (B. terrestris) obtained from a continuous rearing program (provided by Koppert B.V., The Netherlands) and conducted under standardized 
laboratory conditions. The insects were provided ad libitum with commercial pollen (provided by Koppert B.V., The Netherlands) and $30 \%$ sucrose solution as protein source and energy respectively. The parasites (the protozoan flagellates C. bombi) that we used for the experimental infections stemmed from several naturally infected colonies that were laboratory-raised from infected queens. (-)-Nicotine hemisulphate salt ( $\geq 95 \%$ (TLC), $40 \%$ (w/v) in $\mathrm{H}_{2} \mathrm{O}$ (based on free base); N1019 Sigma) was used in all experiments.

\section{Infection experiments}

To determine whether the nectar alkaloid nicotine influences the severity of $C$. bombi infections in bumblebees, we designed two experiments following Manson et al. (2010). In the "Continuous Exposure" test, subjects were first inoculated with $C$. bombi and subsequently fed on a daily supply of nicotine solution or sucrose solution (Control), mimicking the continuous exposure to nectar constituents by a bumblebee worker. In the "Delayed Exposure" test, we first exposed directly $C$. bombi cells to nicotine or control solutions for two hours before inoculating bees, and then we fed them on a sucrose-only solution. We subsequently compared the parasite load in inoculated bumblebees.

We collected faeces from 30 workers from three infected colonies, in order to generate a mix of different parasite strains. The faeces were mixed for one minute with a vortex mixer and the C. bombi cocktail was left to stand at room temperature for two hours. Following this, the supernatant was removed and thoroughly mixed. Cell counts were made using a haemocytometer. Following Manson et al. (2010), faeces were mixed with sucrose solution, generating an inoculum concentration of 2,000 parasite cells/ $\mu$ l. Before inoculation, bees were not given any nutrition for two hours to facilitate infection. Bees derived from two different healthy colonies were screened to ensure that they were free of parasites. Bees were individually presented with a $10 \mu \mathrm{l}$ droplet of inoculum. We observed foragers until the inoculum was consumed in its entirety. Each bee thus ingested approximately 20,000 parasite cells. This value is within the range of $C$. bombi cells present in the faeces of infected workers (Logan et al., 2005), thus mimicking a realistic infection level for transmission to healthy bees.

Post inoculation, in the "Continuous Exposure" test, bees from three colonies were kept individually in Petri dishes and either given a $0.5 \mathrm{ml}$ solution of $2.5 \mathrm{ng} / \mu \mathrm{l}$ nicotine (nectar concentration in the natural range of this alkaloid) in 30\% sucrose solution (Experimental bees, $n=20$ ) or $0.5 \mathrm{ml}$ of plain $30 \%$ sucrose solution (Control bees, $n=20$ ) every day for 10 days. All bees were given a $1 \mathrm{~g}$ pollen ball every day. In the "Delayed Exposure" test, the $C$. bombi inoculum was exposed to nicotine in the dark for two hours before the mixture was offered to bees for ingestion. This mimics a direct exposure of the pathogen to nicotine-laced nectar in a flower. C. bombi cells were placed in a solution of $2.5 \mathrm{ng} / \mu \mathrm{l}$ nicotine in $30 \%$ sucrose (Experimental treatment), and in a solution of $30 \%$ sucrose only (Control treatment). Two hours later, 20 Experimental bees and 20 Control bees were inoculated (for inoculum preparation see above). The treatment emulates a situation where Crithidia cells are deposited on a flower by infected bees and the flower is then visited by a healthy bee. Post inoculation, bees of both groups were kept individually in Petri dishes. They were provided with a fresh pollen ball and $0.5 \mathrm{ml}$ of $30 \%$ sucrose solution every day.
Infection levels were determined 7 and 10 days after inoculation (the period of time in which parasite load peaks and plateaus (Schmid-Hempel \& Schmid-Hempel, 1993)). Each bee was removed from its Petri dish and put into a small glass tube until it defecated. In some individual bees, too little rectal fluid was available after the initial screen; in such cases, we repeated the procedure some hours later. Faeces were transferred to a haemocytometer to count the number of parasite cells.

\section{Laboratory toxicity bioassays}

In order to determine the impact of nicotine consumption on bumblebee survival and any possible interactive effects of dietary toxin consumption and physiological stress (for which we used starvation, as Crithidia has its biggest detrimental impacts on starved bees (Brown et al., 2000)), we exposed bumblebees to artificial nectars with or without nicotine, and then kept them under starvation or with ad libitum food conditions. "Starved bees" were moved individually from their nest into Petri dishes, starved for two hours and fed either with ad libitum $30 \%$ sucrose solution food for 30 minutes (Starved, Control) or $2.5 \mathrm{ng} / \mu \mathrm{l}$ nicotine in $30 \%$ sucrose (Starved, Nicotine). Survival censuses were conducted every hour until all bees were dead. "Ad libitum food bees" were kept individually in Petri dishes, and provided, every day, with $0.5 \mathrm{ml}$ of $30 \%$ sucrose solution plus a fresh pollen ball (Control ad libitum food), $2.5 \mathrm{ng} / \mu \mathrm{l}$ nicotine in $30 \%$ sucrose solution and, again, a fresh pollen ball (Nicotine ad libitum food), $2.5 \mathrm{ng} / \mu \mathrm{l}$ nicotine in $30 \%$ sucrose solution on day 0 and $0.5 \mathrm{ml}$ of $30 \%$ sucrose solution (Nicotine-once ad libitum food) and a fresh pollen ball on a daily basis (Manson et al., 2010). Survival censuses were conducted daily until all bees had died. For each of the five treatments we chose bees from three different young healthy colonies and we randomised bees across treatment groups. Each treatment group was composed of 60 bees (20 bees per colony). Comparisons of the survival parameters of bumblebees in all treatments allowed us to evaluate the effect of nicotine, starvation, and colony membership on survival. We checked for dead bees twice daily and thus such individuals could be weighed within $12 \mathrm{~h}$ of their death using a microscale (Navigator N30330, Ohaus, Pine Brook, USA).

\section{Trade-off between detrimental and beneficial effects of} nicotine

To evaluate whether infected bees benefit from the consumption of nicotine in terms of survival and/or parasite load, we conducted two additional experiments in which infected bumblebees received artificial nectars enriched with nicotine or not and were maintained either starved (three groups of 30 bees, 10 bees from three different colonies, 90 bees in total) or provided with ad libitum food (three groups of 45 bees, 15 bees from three different colonies, 135 bees in total). In both experiments the three groups of bees were inoculated with $C$. bombi as described above and individually kept in Petri dishes under three types of diet (each diet consisted of two solutions dispensed by two different Eppendorf tubes): Control Group: 30\% sucrose only in both dispensers (Suc-Suc group); Exp. Group 1: $2.5 \mathrm{ng} / \mu \mathrm{l}$ nicotine in 30\% sucrose in both dispensers (Nic-Nic group); Exp. Group 2: 30\% sucrose only in one dispenser and $2.5 \mathrm{ng} / \mu \mathrm{l}$ nicotine in $30 \%$ sucrose in the other one (Suc-Nic group). "Starved bees" were fed for 12 days and then starved until all bees were dead. The infection levels were checked on days 7 and 10 after inoculation. Survival censuses were 
conducted every hour (starved bees) and every day (ad libitum food bees) until all bees were dead. At the end of the experiment we quantified total consumption of artificial nectars in each dispenser for each bee. Comparison of the survival parameters of bumblebees in all treatments enabled us to quantify the effect of nicotine and starvation on survival.

\section{Behavioural test}

For testing, each bee colony was housed in a wooden nest box $(28 \times 20 \times 11 \mathrm{~cm})$ connected to a wooden flight arena with a transparent, UV-transmitting Plexiglas lid $(120 \times 100 \times 35 \mathrm{~cm})$, by means of a transparent Plexiglas tube. Shutters along the length of this tube enabled control of the traffic of bees between nest boxes and flight arena (Chittka, 1998). Each bumblebee was individually marked with a coloured numbered disk.

Bees were pre-trained to forage on 12 square transparent plastic flowers of $24 \times 24 \mathrm{~mm}$ (Perspex ${ }^{\circledR}$ Neutral) organized in two patches equidistant from the entrance of the nest. Plastic chips were placed on vertical transparent glass cylinders to raise them above the green floor of the flight arena. During the pre-training all flowers were rewarding with a $15 \mu \mathrm{l}$ droplet of $30 \%$ sucrose solution, placed in a well in the centre of the flower (Raine \& Chittka, 2008). This provided bees with an equal chance to associate both these patches (left and right) with reward during the pre-training period. Bees were allowed to forage freely on these flowers which were refilled as soon as the bees moved on a different artificial flower. In this way bees never experienced an empty flower with the exception of the last visited one. The number of foraging trips (bouts) made in the flight arena by each bee was observed to ensure only strongly motivated foragers visiting both patches (bees that did at least five consecutive foraging bouts) were selected for the experiment (Raine et al., 2006).

After pre-training, the preference of both healthy and infected pre-trained bees was tested for blue plastic flowers (Perspex ${ }^{\circledR} 727$ ) containing nicotine (one patch reward: $2.5 \mathrm{ng} / \mu \mathrm{l}$ nicotine in $30 \%$ sucrose solution; one patch reward: only $30 \%$ sucrose solution). Each bee ( $n=31$ infected bees; $n=28$ healthy bees) was tested individually and one hundred consecutive choices were recorded after the first bout was initiated. Bees were regarded as choosing a flower when they landed and fed from it. Bees approaching or just briefly touching a flower were not considered as choosing that flower. As in the pre-training, flowers were refilled after the bee moved to a different one so that bees never experienced an empty flower with the exception of the last visited one. Flowers were washed between subsequent bees in order to remove possible scent marks (Saleh \& Chittka, 2006). The patch formed by nicotine-containing flowers was swapped from left to right for half the bees of each group (healthy and infected bees). Controlled illumination was provided by high frequency fluorescent lighting [(TMS 24F) lamp with HF-B 236 TLD (4.3 Khz) ballasts, Phillips, Netherlands fitted with Activa daylight fluorescent tubes, Osram] which simulated natural daylight (Dyer \& Chittka, 2004). At the end of the experiment all the bees were sacrificed and the concentration of $C$. bombi in their hind gut was determined (see above).

\section{Statistical analysis}

In the infection experiments, 10 out of 80 bees perished by day 10 for unknown causes. Thus, we quantified the infection intensities of 40 (day 7) and 36 (day 10) bees in the "Continuous Exposure" experiment, and 37 (day 7) and 34 (day 10) bees in the "Delayed Exposure" experiment. To compare differences in parasite load between control and experimental bees 7 and 10 days after inoculation in both experiments we used a generalized linear mixed model (GLMM), with pathogen counts as the within-subject variable and C. bombi exposure to nicotine, time (day 7 and day 10), colony of origin, and bee body weight as explanatory factors. As the data were not normally distributed and homogeneity of variances and sphericity could not be assumed in several cases, we performed corrections according to Huynh-Feldt epsilon (Field, 2009). For the statistical evaluations in the survival experiments, we used the classical survival parameters (i.e. the survival distribution and the median survival time (LT50)). The survival distributions for all treatments were quantified using the Breslow Statistic (Mantel-Cox Test). The following variables were entered in the regression model: colony of origin, body weight, nicotine treatment. For the behavioural experiment, a T test was used to examine differences between preferences for nicotine-rich nectar and control nectar in healthy and infected bees. Spearman rank correlation tests were used to correlate parasite load and nicotine preference. All statistical analyses were done on SPSS $13^{\circledR}$ for Windows.

\section{Results}

\section{Infection experiments}

In both the "Continuous Exposure" and the "Delayed Exposure" tests control bees had comparable levels of $C$. bombi infection (t test, day 7: $t=0.16, \mathrm{df}=37, P=0.98$; day 10: $t=0.92$, $\mathrm{df}=34$, $P=0.36)$. In the "Continuous Exposure" test, a diet laced with nicotine reduced the intensity of $C$. bombi infections in bee workers (Dataset 1). GLMM analysis revealed significant main effects of nicotine and time since inoculation on infection intensity, but not colony of origin or bee body weight (Table 1). At both 7 and 10 days after inoculation, bees exposed to nicotine had infections that were (on average) 1.11 and 0.56 times respectively less intense than control bees (t test, day 7: $n=20-20$, $t=5.2$, df $=38, P<0.001 ;$ day $10: n=18-18, t=3.47$, $d f=34, P=0.001$; Figure 1$)$. Infection intensity increased significantly from day 7 to day 10 , independently of nicotine treatment (no-significant Nicotine and Colony x Time effect; Table 1).

\section{Table 1. "Continuous Exposure" test: results from GLMM analysis of C. bombi population dynamics in bumblebees.}

\begin{tabular}{|l|l|l|l|}
\hline Factor & F-value & Df & P-value \\
\hline Nicotine diet & 35.3 & 1,61 & 0.001 \\
\hline Time since inoculation & 16.2 & 1,61 & 0.001 \\
\hline Bee body weight & 1.07 & 1,61 & 0.3 \\
\hline Colony & 0.46 & 1,65 & 0.8 \\
\hline Interactions & - & - & N.S. \\
\hline
\end{tabular}




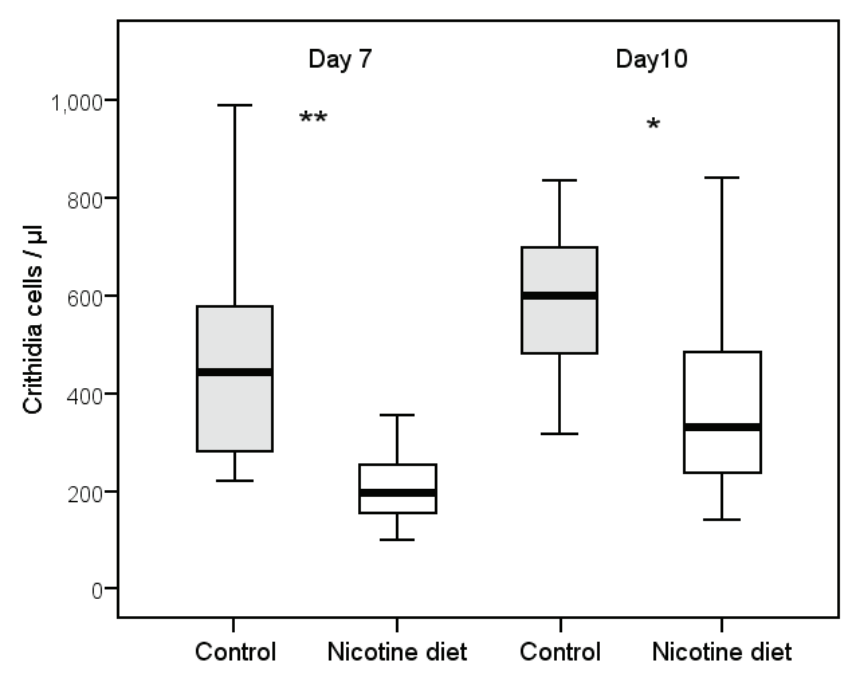

Figure 1. Intensity of $C$. bombi infections in bumblebees that received either a nicotine diet (Experimental bees, $n=20$ ) or a sucrose only diet (Control bees, $\boldsymbol{n}=\mathbf{2 0}$ ). Faeces were checked after 7 days and 10 days post inoculation. Box plots show medians, $25^{\text {th }}$ and $75^{\text {th }}$ percentiles ( ${ }^{* *} P<0.001 ;{ }^{*} P=0.001$ ).

In the "Delayed Exposure" test, exposing C. bombi to nicotine for two hours before inoculation had no effect on parasite load (Table 2) (Dataset 1). At 7 days and 10 days post-inoculation, bees exposed to nicotine had infections that on average were as intense as those of control bees ( $\mathrm{t}$ test, day 7: $n=19-18, t=0.16$, $\mathrm{df}=35, P=0.87$; day $10: n=17-17, t=-0.69, \mathrm{df}=32, P=0.5$; Figure 2). Infections intensified significantly from day 7 to day 10 , independently of nicotine treatment (there was no significant Nicotine $\mathrm{x}$ Time and Colony $\mathrm{x}$ Time effects; Table 2). Taken together, these findings prove the antimicrobial activity of nicotine against the pathogen when ingested by bumblebees, but also indicate that when pathogens are exposed to the alkaloid prior to host ingestion the protozoan's viability is not strongly affected.

Table 2. Delayed Exposure test: results from the GLMM analysis of C. bombi population dynamics in bumblebees.

\begin{tabular}{|l|l|l|l|}
\hline Factor & F-value & Df & P-value \\
\hline Nicotine pre-treatment & 0.02 & 1,62 & 0.8 \\
\hline Time since inoculation & 27.1 & 1,60 & 0.001 \\
\hline Bee body weight & 0.52 & 1,62 & 0.4 \\
\hline Colony & 2.9 & 1,62 & 0.1 \\
\hline Interactions & - & - & N.S. \\
\hline
\end{tabular}

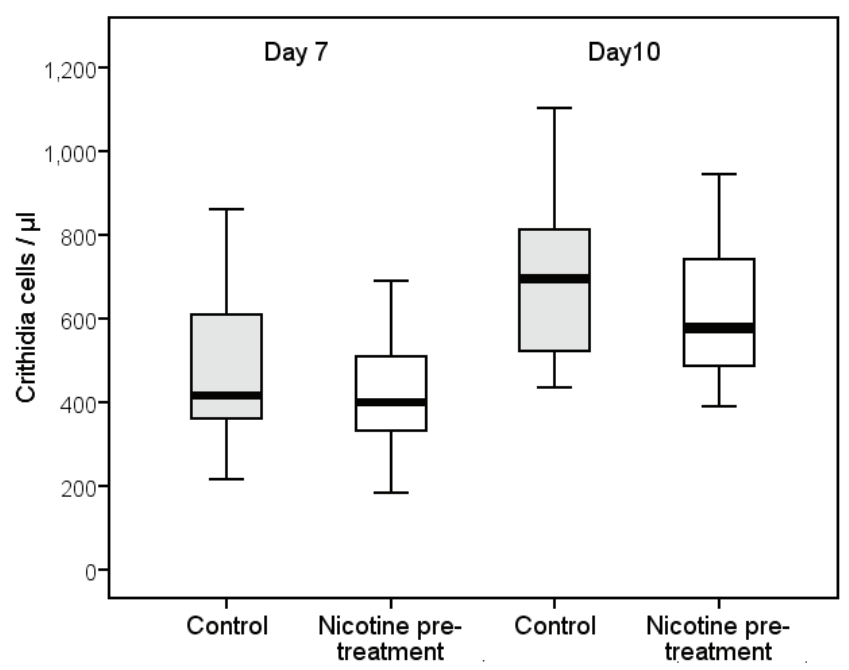

Figure 2. Intensity of C. bombi infections in bumblebees inoculated with pathogens previously exposed to nicotine for two hours (Experimental bees, $n=20$ ) or to a control sucrose diet (Control bees, $\boldsymbol{n}=\mathbf{2 0}$ ). Faeces were checked after 7 days and 10 days post inoculation. Box plots show medians, $25^{\text {th }}$ and $75^{\text {th }}$ percentiles $(P=$ N.S. $)$.

\section{Dataset 1. Infection experiments}

http://dx.doi.org/10.5256/f1000research.6262.d44610

Effect of nicotine on parasite load in infected bumblebees.

Laboratory toxicity bioassays

In the "Starved" test, statistical evaluation of the survivorship of control and experimental bumblebees revealed that a nicotine diet was not a significant predictor of mortality (Log-rank Mantel Cox test $\chi^{2}=0.21$, df $=1, P=0.88$; Figure 3A) (Dataset 2). Furthermore no effect of colony of origin and bee body weight on mortality was found (GLM, treatments: $\mathrm{F}=1.1, \mathrm{df}=1, P=0.29$; Colony $\mathrm{F}=0.46$, $\mathrm{df}=2, P=0.63$; body weight: $\mathrm{F}=0.19$, df $=1, P=0.66)$. The median lethal time (LT50) for the two groups did not differ (control LT50: 39 hours, exp. bees LT50 $=37$ hours).

In the "ad libitum food" test a Log-rank Mantel Cox test showed that a daily diet including nicotine was a significant predictor of mortality $\left(\chi^{2}=11.56\right.$, df $=2, n=180, P=0.003$; Figure 3B) (Dataset 2). Pairwise statistical comparisons revealed that bees fed consistently with nicotine had significantly lower survivorship than 'Nicotine-once' and 'Control bumblebees' $(P=0.001)$, while the latter two experimental groups did not differ $(P=0.86)$. LT50 of bees fed daily with nicotine was 39 days while 'Nicotine-once' bumblebees and control bees had a LT50 of 44 and 43 days respectively. Colony of origin and 
A

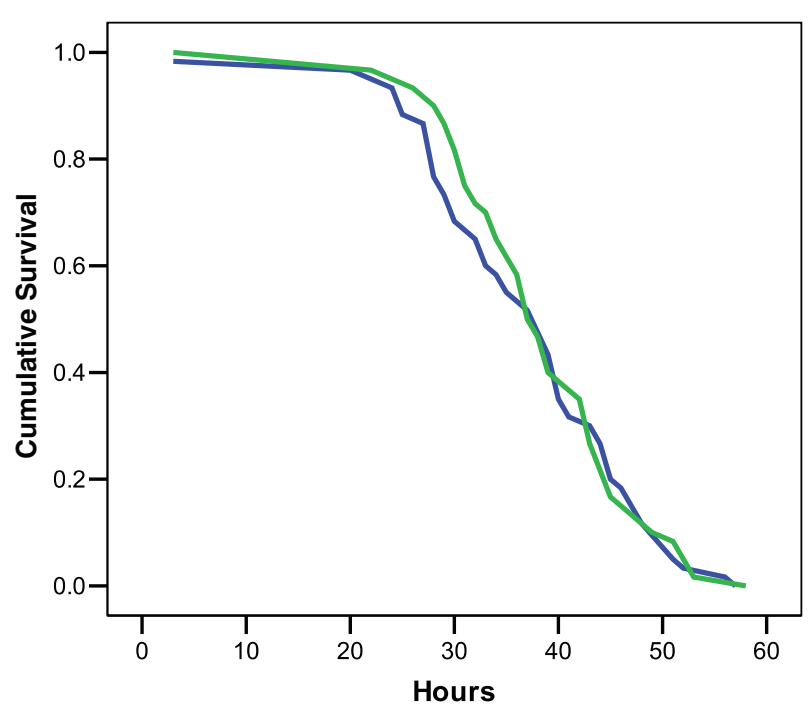

B Survival Functions

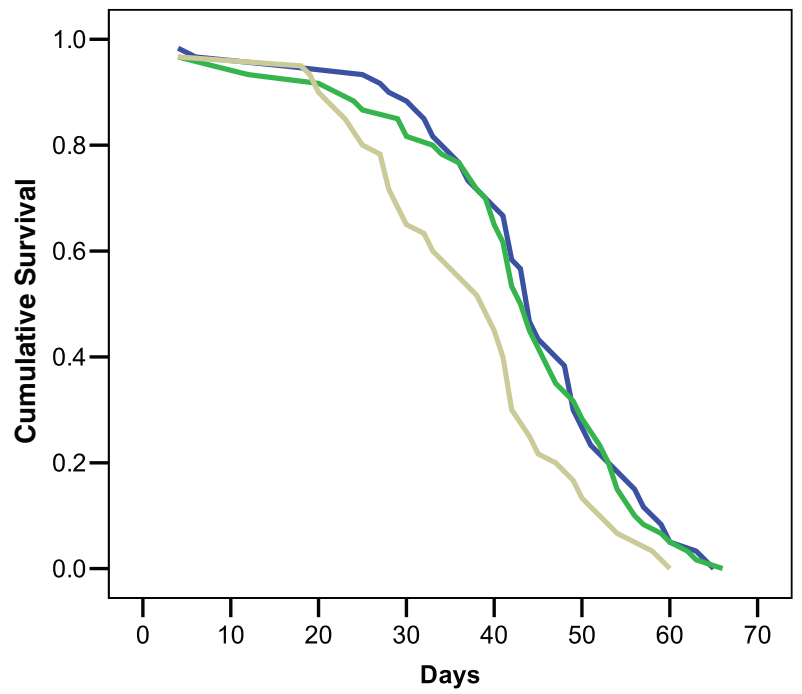

Figure 3. A: Cumulative survival of healthy bees fed with a sucrose solution with (blue line) or without (green line) nicotine and starved. B: Cumulative survival of healthy bees that received a daily diet of sucrose solution with (beige line), or without nicotine (blue line), or a single dose of nicotine on day one (green line).

body weight did not affect bee mortality (GLM, Colony: $\mathrm{F}=0.35$, df $=2, P=0.71$; body weight: $\mathrm{F}=1.90$, df $=1, P=0.16$ ), but we found a significant interaction between body weight and treatment (larger bees were less susceptible to nicotine, GLM, F = 5.12, $\mathrm{df}=1$, $P=0.025)$. Taken together, these findings indicate that nicotine has some detrimental effects on healthy bumblebees if consistently consumed for weeks but also that these effects are possibly quite weak.

\section{Dataset 2. Revision 1. Laboratory toxicity bioassays \\ http://dx.doi.org/10.5256/f1000research.6262.d48008}

Effect of nicotine on healthy bee survival. The 'Body weight (ad libitum)' column previously contained duplicate data, the correct values have now been reinstated.

\section{Trade-off between detrimental and beneficial effects of} nicotine

In both "ad libitum food bees" and "starved bees" tests, a nicotine diet was not a significant predictor of survival (Log-rank Mantel Cox test: "ad libitum food bees": $n=135$, Nic-Nic vs Nic-Suc $\chi^{2}=0.3$, $P=0.6$; Nic-Nic vs Suc-Suc $\chi^{2}=0.01, P=0.9$; Nic-Suc vs Suc-Suc $\chi^{2}=0.7, P=0.4$; "Starved bees", $n=76$; Nic-Nic vs Nic-Suc $\chi^{2}=0.4$, $P=0.5$; Nic-Nic vs Suc-Suc $\chi^{2}=0.1, P=0.7$; Nic-Suc vs Suc-Suc $\chi^{2}=0.01, P=0.9$ ) (Dataset 3 ). Furthermore no effect of colony of origin on mortality was found (GLM, "ad libitum food bees": $\mathrm{F}=1.4$, $\mathrm{df}=2, P=0.24$; "Starved bees": GLM, $\mathrm{F}=2.02, \mathrm{df}=2, P=0.14$ ). The median lethal time LT50 for the three groups did not differ ("ad libitum food bees": Suc-Suc LT50: 22 days, Nic-Suc LT50 = 23, days, Nic-Nic LT50 = 22; "Starved bees": Suc-Suc LT50: 25 hours, Nic-Suc LT50 $=28$ hours, Nic-Nic LT50 $=31$ hours).

GLMM analysis revealed significant main effects of treatment $(\mathrm{df}=2, \mathrm{~F}=3.46, P=0.03)$ and time since inoculation $(\mathrm{df}=1, \mathrm{~F}=57.3$, $P<0.001)$ on infection intensity, but not colony of origin $(\mathrm{df}=2$, $\mathrm{F}=1.64, P=1.96)$. No interaction between diet, time and colony was significant. Overall bees caged in Petri dishes consumed less food over the entire duration of the experiment if exposed to nicotine (Anova test: $\mathrm{F}=9.68, n=90, \mathrm{df}=2,87, P=0.001$; Dunnett T3 post hoc test: Suc-Suc vs Nic-Nic and Suc-Suc vs Nic-Suc $P<0.001$ ) (Dataset 4). Infected bees showed a slight preference $(54 \pm 17 \%)$ for sucrose solution laced with nicotine (Paired samples t test, $\mathrm{t}=2.14, \mathrm{df}=29, n=30, P=0.04)$.

Overall these findings indicate that, even though nicotine reduces the parasite load in infected bees, and such bees have a slight preference for sucrose solution laced with the alkaloid, there is no net benefit in term of survival for infected bees.

Dataset 3. Trade-off between detrimental and beneficial effects of nicotine

http://dx.doi.org/10.5256/f1000research.6262.d44613

Dietary nicotine effect on parasite load and life expectancy in infected bumblebees. 


\section{Dataset 4. Diet preference of caged bees}

http://dx.doi.org/10.5256/f1000research.6262.d44614

Caged infected bee preference for nicotine-laced nectars

\section{Preference of freely flying bees for nicotine-laced flowers}

Infected bumblebees allowed to forage on plastic flowers showed a significantly increased propensity to visit nicotine rewarding flowers when compared to healthy bees ( $\mathrm{t}$ test, $n=31,28, \mathrm{t}=-2.4, \mathrm{df}=57$, $P=0.016$; Figure 4) (Dataset 5). Indeed on 100 consecutive choices infected bees visited the nicotine flowers on average $64.5 \pm 13.8$ (s.d.) times while healthy bees visited them $54.8 \pm 19.4$ (s.d.) times. Since test bees were introducing nicotine into the colony throughout testing, we controlled for prior exposure to nicotine effect on nicotine preference. Bees tested later in the experiment did not show a higher or lower nicotine preference (Spearman test, Infected bees: $\rho=-0.21, n=31, P=0.3$; Control bees $n=28$, $\rho=0.041, P=0.8$ ). There was no correlation between pathogen load and the propensity of infected bees to visit flowers with nicotine-rich artificial nectar (Spearman test: $n=31, \rho=0.19$, df $=29, P=0.28$ ).

\section{Dataset 5. Behavioural test}

http://dx.doi.org/10.5256/f1000research.6262.d44615

Percentage of preferred flowers rewording with nicotine-rich artificial nectar by infected and healthy bees.

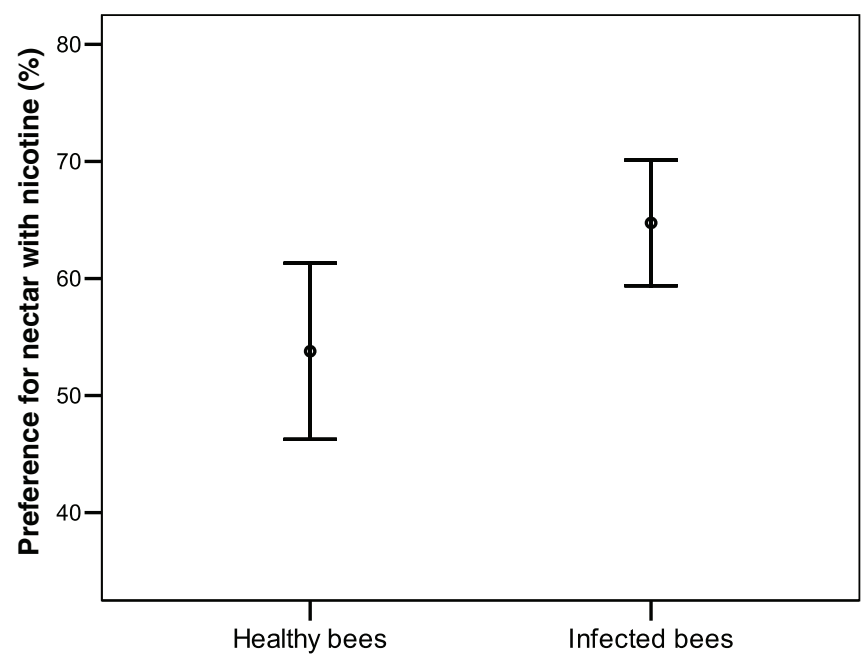

Figure 4. Percentage of preferred flowers rewording with nicotinerich artificial nectar by infected bees $(n=31)$ and healthy bees ( $\boldsymbol{n}=\mathbf{2 8}$ ), (t test, $\boldsymbol{P}=\mathbf{0 . 0 1 6}$ ). Infected bees visited nicotine-containing flowers $64.5 \pm 13.8$ (s.d.) times while healthy bees visited them $54.8 \pm 19.4$ (s.d.) times.

\section{Discussion}

Here we demonstrate that parasitized bumblebees modify their diet preference and foraging behaviour, delaying the development of an infection. In our experimental setup the parasite infection induced an increased consumption of nicotine both in individually caged as well as in foraging bumblebees. Healthy bees exposed to nicotine suffer an appreciable cost, also in line with the key criteria for self-medication (Abbott, 2014; Clayton \& Wolfe, 1993; Singer et al., 2009). However, despite this preferential ingestion of a "nonnutritive" antimicrobial alkaloid by infected bees, this behaviour appears to be of limited efficiency since dietary nicotine does not fully cure C. bombi infection, or increase longevity of infected bees, similarly to a recent study on the North American Bombus impatiens (Richardson et al., 2015). Nonetheless bumblebees in our study exhibited a reduced $C$. bombi load after daily consumption of the alkaloid making the existence of a potential self-medication phenomenon plausible. In nature, infection entails an array of costs and higher mortality under stressful conditions (Alghamdi et al., 2008; Brown et al., 2000; Brown et al., 2003; Gegear et al., 2006). As a consequence, any reduction in the severity or progression of infection in bees, induced by mechanisms such as the consumption of nectar containing curative alkaloids (e.g. gelsemine (Manson et al., 2010), anabasine and nicotine (Richardson et al., 2015)), might be beneficial in terms of fitness for both bees and colonies.

Even if we cannot completely exclude that the limited effect of nicotine is due to the initial challenge being too strong for the nicotine to have a measurable influence on life expectancy, both nicotine concentration and Crithidia inocula used in our study simulated natural doses. It is, however, possible that the nicotine concentration available to workers within the colony is substantially different from that found in flowers. At one end of the scale of possibilities, nicotine-laced nectar might be regurgitated into honeypots containing nicotine-free nectar, resulting in further dilution of the nicotine concentration and even lower anti-microbial effects. On the other hand, if some individual foragers that have discovered alkaloidcontaining nectar deposit it predominantly into certain honeypots, and concentration is further increased by evaporation and possibly modified by enzymatic addition, then such honeypots could contain substantially higher nicotine concentrations than found in floral nectar (Thomson, 2015). It is possible that such honeypots could be a kind of colony 'pharmacy' specifically used for selfmedication of infected workers, or to feed larvae to limit the spread of an infection within the colony (James Thomson, personal communication). Similar considerations apply to pollen, which might also contain alkaloids with antimicrobial properties (Thomson, 2015). Additional field and mesocosm tests, as well measurements of alkaloid concentration in colony honeypots are thus needed to evaluate the actual concentrations to which different colony members and the brood are exposed, and thus to clarify the actual benefits of differential foraging for such substances.

Nicotine also has a costly effect on uninfected individuals, as shown by our toxicological assays. A daily diet containing nicotine, lasting more than two months, reduced the life expectancy of bumblebees, and this effect was stronger in smaller bees. This might possibly be aggravated in the wild, where bees are exposed to other stressors and do not have access to ad libitum food. However, we note that differences in mortality rate between controls and nicotine-treated bees started to be evident only after 20 days from the first exposure suggesting that in nature this detrimental effect may be mitigated due to the relatively short lifespan of foragers in the wild (da Silva-Matos \& Garófalo, 2000). Moreover, in nature, bees 
are unlikely to visit a single nectar source continuously for weeks as in our experiments, further reducing the negative effect of nicotine intake. In infected bumblebees, which show a shorter lifespan than healthy ones, the detrimental effect of nicotine is no longer evident suggesting that detoxification costs might be counterbalanced by the advantages in slowing the progression of the infection. However, contrary to our prediction, we found no trade-off between costs and benefits in terms of survival, and infected bumblebee lifespan was not affected by the consumption on nicotine. Our analysis focussed on individual bumblebees in isolation and there might be many other subtle long term benefits we have not explored, such as possible benefits at the colony level. It might be that lifespan analysis of forager bumblebees would be different in a social setting. Infected bumblebees have impaired learning abilities (Alghamdi et al., 2008; Gegear et al., 2006) and a reduction in parasite load might affect foraging efficiency or nursing ability, in turn enhancing colony productivity. Moreover, nicotine might be beneficial in slowing the progression of the infection through a colony, allowing, for example, the queen to lay more eggs or the larvae to prosper.

The cost imposed by the consumption of nicotine in our experiments may explain why healthy bees did not constantly consume high doses of nicotine (Tiedeken et al., 2014). Similarly, infected bees kept in Petri dishes reduced the overall uptake of food if exposed to nicotine. This is surprising given that those bumblebees also had a slight preference for sucrose solution laced with the alkaloid, and free-flying healthy bumblebees were not repelled by artificial nectar laced with nicotine. While these behavioural preferences may be explained by the impact that some nectar alkaloids, including nicotine, have on learning and memory in bees (Chittka \& Peng, 2013; Thany \& Gauthier, 2005; Wright et al., 2013), the mechanism behind the overall reduced consumption caused by nicotine remains unexplained. In humans at least, it is well established that nicotine has appetite-reducing effects (Jessen et al., 2005).

Currently it is unclear how nicotine acts on $C$. bombi. Nicotine is a highly toxic molecule (Benowitz, 1998) that acts against a wide spectrum of bacterial and fungal pathogens (Pavia et al., 2000). House sparrows and several finch species, for example, add smoked cigarette butts retaining substantial amounts of nicotine to their nests to reduce mite infestations (Suárez-Rodríguez et al., 2013). While our in vivo microbiological experiments prove the antimicrobial activity of nicotine against the pathogen when ingested, they also suggest that nicotine does not directly interfere with the protozoan's viability, at least when measured as infectivity. As suggested by Manson et al. (2010), who found similar effects of the natural alkaloid gelsemine, an alkaloid-rich diet might increase a bee's excretion rate, as occurs for nectarivorous bird (Tadmor-Melamed et al., 2004), effectively "flushing" C. bombi cells from the gut. Another possibility might be that nicotine, or perhaps its metabolites, directly modify the mid-gut epithelium or the environment of its lumen, making it less suitable for the parasite.

In conclusion, we showed that when infected, bumblebees use a nectar alkaloid, slowing the progression of the infection. Nicotine consumption did not affect bee lifespan but the reduction in the parasite load may have other likely subtle benefits both for individual bees and colony. Recent findings confirm the suggestion that the preferential ingestion of natural nectar secondary metabolites in pollinators might play a key role in mediating pathogen transmission within and between colonies (Richardson et al., 2015) or interactions among pollinators and their parasites (Manson et al., 2010). The observed increased ingestion of a nectar alkaloid might be a generalized response to sickness and not just to Crithidia. Similarly, our results and other recent studies (Gherman et al., 2014; Richardson et al., 2015) provide potential evidence for self-medication mediated by the consumption of plant secondary metabolites. Yet, the conditions under which nicotine and other alkaloids consumption provides benefits to either bees or plants remain to be identified. We thus believe that a careful approach to interpreting impacts of plant metabolites on insect parasites is warranted. The contention that secondary metabolites in nectar may be under selection from pollinators, or used by plants to enhance their own reproductive success (Chittka \& Peng, 2013; Thomson et al., 2015; Wright et al., 2013), should ideally be confirmed with further studies, which examine the impacts of these metabolites on both bee and plant fitness under field-realistic conditions.

\section{Data availability}

F1000Research: Dataset 1. Infection experiments, 10.5256/f1000 research.6262.d44610 (Baracchi et al., 2015a).

F1000Research: Dataset 2. Revision 1. Laboratory toxicity bioassays, 10.5256/f1000research.6262.d48008 (Baracchi et al., 2015b).

F1000Research: Dataset 3. Trade-off between detrimental and beneficial effects of nicotine, 10.5256/f1000research.6262.d44613 (Baracchi et al., 2015c).

F1000Research: Dataset 4. Diet preference of caged bees, 10.5256/ f1000research.6262.d44614 (Baracchi et al., 2015d).

F1000Research: Dataset 5. Behavioural test, 10.5256/f1000research. 6262.d44615 (Baracchi et al., 2015e).

\section{Author contributions}

D.B. conceived the study and carried out the experiments. D.B. and M.J.F.B. designed the experiments. L.C. made significant contributions to the interpretation of the data. All authors contributed in writing the first version of the manuscript and have agreed the final content. L.C. revised the paper.

\section{Competing interests}

No competing interests were disclosed.

\section{Grant information}

D.B. was supported by a Marie Curie Intra European Fellowship within the 7th European Community Framework Programme.

The authors confirm that the funders had no role in study design, data collection and analysis, decision to publish, or preparation of the manuscript.

\section{Acknowledgements}

The authors thank Anna Woodhouse for helping in behavioural experiments, Dr. Gemma Baron for providing Crithidia samples, Dr. Caroline Brennan for nicotine solution, Thomas Ingraham (an employee of F1000Research) and three referees for comments on the manuscript. 
Abbott J: Self-medication in insects: current evidence and future perspectives. Ecol Entomol. 2014; 39(3): 273-280.

Publisher Full Text

Alghamdi A, Dalton L, Phillis A, et al:: Immune response impairs learning in free-flying bumble-bees. Biol Lett. 2008; 4(5): 479-481.

PubMed Abstract | Publisher Full Text | Free Full Text

Baracchi D, Brown MJF, Chittka L: Dataset 1 in: Weak and contradictory effects of self-medication with nectar nicotine by parasitized bumblebees. F1000Research. 2015a.

Data Source

Baracchi D, Brown MJF, Chittka L: Dataset 2 in: Behavioural evidence for selfmedication in bumblebees? F1000Research. 2015b.

Data Source

Baracchi D, Brown MJF, Chittka L: Dataset 3 in: Weak and contradictory effects of self-medication with nectar nicotine by parasitized bumblebees. F1000Research. 2015c

Data Source

Baracchi D, Brown MJF, Chittka L: Dataset 4 in: Weak and contradictory effects of self-medication with nectar nicotine by parasitized bumblebees. F1000Research. 2015d.

Data Source

Baracchi D, Brown MJF, Chittka L: Dataset 5 in: Weak and contradictory effects of self-medication with nectar nicotine by parasitized bumblebees. F1000Research. 2015e.

Data Source

Benowitz NL: Nicotine safety and toxicity. Oxford University Press: New York, USA. 1998.

Reference Source

Bernays EA, Singer MS: Insect defences: taste alteration and endoparasites. Nature. 2005; 436(7050): 476.

PubMed Abstract | Publisher Full Tex

Brown MJF, Loosli R, Schmid-Hempel P: Condition-dependent expression of virulence in a trypanosome infecting bumblebees. Oikos. 2000; 91(3): 421-427.

Publisher Full Text

Brown MJF, Schmid-Hempel R, Schmid-Hempel P: Strong context-dependent virulence in a host-parasite system: reconciling genetic evidence with theory. J Anim Ecol. 2003; 72(6): 994-1002.

Publisher Full Tex

Cameron SA, Lozier JD, Strange JP, et al.: Patterns of widespread decline in North American bumble bees. Proc Natl Acad Sci USA. 2011; 108(2): 662-667. PubMed Abstract | Publisher Full Text | Free Full Text

Chittka L: Sensorimotor learning in bumblebees: long-term retention and reversal training. J Exp Biol. 1998; 201(4): 515-524.

Reference Source

Chittka L, Peng F: Neuroscience. Caffeine boosts bees' memories. Science. 2013; 339(6124): 1157-1159.

PubMed Abstract | Publisher Full Text

Clayton DH, Wolfe ND: The adaptive significance of self-medication. Trends Ecol Evol. 1993; 8(2): 60-63.

PubMed Abstract | Publisher Full Text

Cowan MM: Plant products as antimicrobial agents. Clin Microbiol Rev. 1999 12(4): 564-582.

PubMed Abstract | Free Full Text

da Silva-Matos EV, Garófalo CA: Worker life tables, survivorship, and longevity in colonies of Bombus (Fervidobombus) atratus (Hymenoptera: Apidae). Rev Biol Trop. 2000; 48(2-3): 657-663.

PubMed Abstract

de Miranda JR, Genersch E: Deformed wing virus. J Invertebr Pathol. 2010;

103(Suppl 1): S48-S61.

PubMed Abstract | Publisher Full Text

de Roode JC, Lefèvre T: Behavioral immunity in insects. Insects. 2012; 3(3):

789-820.

Publisher Full Text

de Roode JC, Lefèvre T, Hunter MD: Ecology. Self-medication in animals.

Science. 2013; 340(6129): 150-151.

PubMed Abstract | Publisher Full Tex

Debban CL, Dyer KA: No evidence for behavioural adaptations to nematode parasitism by the fly Drosophila putrida. J Evol Biol. 2013; 26(8): 1646-1654. PubMed Abstract | Publisher Full Tex

Detzel A, Wink M: Attraction, deterrence or intoxication of bees (Apis mellifera) by plant allelochemicals. Chemoecology. 1993; 4(1): 8-18.

Publisher Full Text

Durrer S, Schmid-Hempel P: Shared use of flowers leads to horizontal pathogen transmission. Proc Biol Sci. 1994; 258(1353): 299-302.

Publisher Full Text

Dyer AG, Chittka L: Bumblebees (Bombus terrestris) sacrifice foraging speed

to solve difficult colour discrimination tasks. J Comp Physiol A Neuroethol Sens

Neural Behav Physiol. 2004; 190(9): 759-763.

PubMed Abstract | Publisher Full Text
Field A: Discovering statistics using SPSS,. Sage publications 2009.

Reference Source

Fürst MA, McMahon DP, Osborne JL, et al.: Disease associations between honeybees and bumblebees as a threat to wild pollinators. Nature. 2014; 506(7488): 364-366

PubMed Abstract | Publisher Full Text | Free Full Text

Gegear RJ, Otterstatter MC, Thomson JD: Bumble-bee foragers infected by a gut parasite have an impaired ability to utilize floral information. Proc Biol Sci. 2006; 273(1590): 1073-1078.

PubMed Abstract | Publisher Full Text | Free Full Text

Gherman BI, Denner A, Bobiş O, et al:: Pathogen-associated self-medication behavior in the honeybee Apis mellifera. Behav Ecol Sociobiol. 2014; 68(11): 1777-1784. Publisher Full Text

Hadacek F: Secondary metabolites as plant traits: current assessment and future perspectives. Crit Rev Plant Sci. 2002; 21(4): 273-322.

Publisher Full Text

Jessen A, Buemann B, Toubro S, et al: The appetite-suppressant effect of nicotine is enhanced by caffeine. Diabetes Obes Metab. 2005: 7(4): 327-333.

PubMed Abstract | Publisher Full Text

Lefèvre T, Oliver L, Hunter MD, et al:: Evidence for trans-generational

medication in nature. Ecol Lett. 2010; 13(12): 1485-1493.

PubMed Abstract | Publisher Full Text

Logan A, Ruiz-González MX, Brown MJF: The impact of host starvation on parasite development and population dynamics in an intestinal trypanosome

parasite of bumble bees. Parasitology. 2005; 130(Pt 6): 637-642.

PubMed Abstract | Publisher Full Tex

Lozano GA: Parasitic stress and self-medication in wild animals. Adv Stud Behav. 1998; 27: 291-318.

Reference Source

Manson JS, Otterstatter MC, Thomson JD: Consumption of a nectar alkaloid reduces pathogen load in bumble bees. Oecologia. 2010; 162(1): 81-89. PubMed Abstract | Publisher Full Text

McArt SH, Koch H, Irwin RE, et al.: Arranging the bouquet of disease: flora traits and the transmission of plant and animal pathogens. Ecol Lett. 2014; 17(5): 624-636.

PubMed Abstract | Publisher Full Tex

McMahon DP, Fürst MA, Casper J, et al:: A sting in the spit: widespread cross-infection of multiple RNA viruses across wild and managed bees. $J$ Anim Ecol. 2015; 84: 615-624.

PubMed Abstract | Publisher Full Text

Michalakis Y: Parasitism and the evolution of life-history traits. In Thomas F Guégan JF Renaud F (eds), Ecology and evolution of parasitism. Oxford University Press: Oxford, UK. 2009.

Reference Source

Milan NF, Kacsoh BZ, Schlenke TA: Alcohol consumption as self-medication against blood-borne parasites in the fruit fly. Curr Biol. 2012; 22(6): 488-493. PubMed Abstract | Publisher Full Text | Free Full Text

Mooney KA, Agrawal AA: Plant genotype shapes ant-aphid interactions: implications for community structure and indirect plant defense. Am Nat. 2008; 171(6): E195-E205.

PubMed Abstract | Publisher Full Text

Moore J: Parasites and the behavior of animals. Oxford University Press: New York, USA. 2002.

Reference Source

Naef R, Jaquier A, Velluz A, et al:: From the linden flower to linden honey--volatile constituents of linden nectar, the extract of bee-stomach and ripe honey. Chem Biodivers. 2004; 1(12): 1870-1879.

PubMed Abstract | Publisher Full Text

Oliver KM, Degnan PH, Burke GR, et al.: Facultative symbionts in aphids and the horizontal transfer of ecologically important traits. Annu Rev Entomol. 2010; 55 247-266.

PubMed Abstract | Publisher Full Text

Otterstatter MC, Thomson JD: Contact networks and transmission of an intestinal pathogen in bumble bee (Bombus impatiens) colonies. Oecologia. 2007; 154(2): 411-421.

PubMed Abstract | Publisher Full Text

Pavia CS, Pierre A, Nowakowski J: Antimicrobial activity of nicotine against a spectrum of bacterial and fungal pathogens. J Med Microbiol. 2000; 49(7): 675-676. PubMed Abstract

Raine NE, Chittka L: The correlation of learning speed and natural foraging success in bumble-bees. Proc Biol Sci. 2008; 275(1636): 803-808.

PubMed Abstract | Publisher Full Text | Free Full Text

Raine NE, Ings TC, Ramos-Rodriguez O, et al.: Intercolony variation in learning performance of a wild British bumblebee population (Hymenoptera: Apidae: Bombus terrestris audax). Entomol Gen. 2006; 28(4): 241-256.

Publisher Full Text

Richardson LL, Adler LS, Leonard AS, et al:: Secondary metabolites in floral nectar reduce parasite infections in bumblebees. Proc Biol Sci. 2015; 282(1803): pii: 20142471.

PubMed Abstract | Publisher Full Text | Free Full Text 
Rodriguez E, Wrangham R: Zoopharmacognosy: the use of medicinal plants by animals. In Downum KR, Romeo JT, Stafford HA (eds), Phytochemical potential of tropical plants. Springer: USA. 1993; 27: 89-105.

Publisher Full Text

Rosenkranz P, Aumeier P, Ziegelmann B: Biology and control of Varroa destructor. J Invertebr Pathol. 2010; 103(Suppl 1): S96-S119.

PubMed Abstract | Publisher Full Text

Saleh N, Chittka L: The importance of experience in the interpretation of conspecific chemical signals. Behav Ecol Sociobiol. 2006; 61(2): 215-220. Publisher Full Text

Schmid-Hempel P: Parasites in social insects. Princeton University Press: New Jersey. USA. 1998

Reference Source

Schmid-Hempel P, Schmid-Hempel R: Transmission of a pathogen in Bombus terrestris, with a note on division of labour in social insects. Behav EcOl

Sociobiol. 1993; 33(5): 319-327.

Publisher Full Text

Schmid-Hempel R, Eckhardt M, Goulson D, et al.: The invasion of southern South America by imported bumblebees and associated parasites. J Anim Ecol. 2013; 83(4): 823-837.

PubMed Abstract | Publisher Full Tex

Shykoff JA, Schmid-Hempel P: Incidence and effects of four parasites in natura populations of bumble bees in Switzerland. Apidologie. 1991; 22(2): 117-125.

Publisher Full Tex

Simone-Finstrom MD, Spivak M: Increased resin collection after parasite challenge: a case of self-medication in honey bees? PLOS One. 2012; 7(3) e34601.

PubMed Abstract | Publisher Full Text | Free Full Text

Singer MS, Mace KC, Bernays EA: Self-medication as adaptive plasticity: increased ingestion of plant toxins by parasitized caterpillars. PLoS One. 2009; 4(3): e4796. PubMed Abstract | Publisher Full Text | Free Full Text

Smilanich AM, Mason PA, Sprung L, et al:: Complex effects of parasitoids on pharmacophagy and diet choice of a polyphagous caterpillar. Oecologia. 2011 165(4): 995-1005.

PubMed Abstract | Publisher Full Tex
St Leger RJ: Integument as a barrier to microbial infections. In Binnington K, Retnakara A (eds), Physiology of the insect epidermis CSIRO. 1991.

Suárez-Rodríguez M, López-Rull I, Garcia CM: Incorporation of cigarette butts into nests reduces nest ectoparasite load in urban birds: new ingredients for an old recipe? Biol Lett. 2013; 9(1): 20120931.

PublMed Abstract | Publisher Full Text | Free Full Text

Tadmor-Melamed H, Markman S, Arieli A, et al:: Limited ability of Palestine sunbirds Nectarinia osea to cope with pyridine alkaloids in nectar of tree tobacco Nicotiana glauca. Funct Ecol. 2004; 18(6): 844-850.

Publisher Full Text

Thany SH, Gauthier M: Nicotine injected into the antennal lobes induces a rapid modulation of sucrose threshold and improves short-term memory in the honeybee Apis mellifera. Brain Res. 2005; 1039(1-2): 216-219.

PubMed Abstract | Publisher Full Text

Thomson JD: Referee Report For: Weak and contradictory effects of selfmedication with nectar nicotine by parasitized bumblebees [v1; ref status: indexed, http://f1000r.es/56I]. F1000Res. 2015; 4: 73

Publisher Full Text

Thomson JD, Draguleasa MA, Tan MG: Flowers with caffeinated nectar receive more pollination. Arthropod Plant Interact. 2015; 9(1): 1-7.

Publisher Full Text

Tiedeken EJ, Stout JC, Stevenson PC, et al.: Bumblebees are not deterred by ecologically relevant concentrations of nectar toxins. J Exp Biol. 2014; 217(pt 9): 1620-1625.

PubMed Abstract | Publisher Full Text | Free Full Text

Tragust S, Mitteregger B, Barone V, et al:: Ants disinfect fungus-exposed brood by oral uptake and spread of their poison. Curr Biol. 2013; 23(1): 76-82. PubMed Abstract | Publisher Full Text

Wrangham RW: Relationship of chimpanzee leaf-swallowing to a tapeworm infection. Am J Primatol. 1995; 37(4): 297-303.

Publisher Full Text

Wright GA, Baker DD, Palmer MJ, et al: Caffeine in floral nectar enhances a pollinator's memory of reward. Science. 2013; 339(6124): 1202-1204. PubMed Abstract | Publisher Full Text 


\section{Open Peer Review}

\section{Current Peer Review Status:}

\section{Version 2}

Reviewer Report 22 September 2015

https://doi.org/10.5256/f1000research.7009.r8767

(C) 2015 Simone-Finstrom M. This is an open access peer review report distributed under the terms of the Creative Commons Attribution License, which permits unrestricted use, distribution, and reproduction in any medium, provided the original work is properly cited.

Michael Simone-Finstrom

Department of Entomology, North Carolina State University, Raleigh, NC, USA

Competing Interests: No competing interests were disclosed.

I confirm that I have read this submission and believe that I have an appropriate level of expertise to confirm that it is of an acceptable scientific standard.

Reviewer Report 08 July 2015

https://doi.org/10.5256/f1000research.7009.r9415

(C) 2015 Thomson J. This is an open access peer review report distributed under the terms of the Creative Commons Attribution License, which permits unrestricted use, distribution, and reproduction in any medium, provided the original work is properly cited.

\section{James D. Thomson}

Department of Ecology and Evolutionary Biology, University of Toronto, Toronto, ON, Canada

I have now looked through the new version and can happily remove my reservations regarding the earlier version. My main biological concern-that dosages of secondary metabolites need to be considered in the light of honeypot dynamics-is now given an intelligent discussion. The problems with table entries and figure labels have also been corrected. I did not see a need to change the title, but I agree that the new title is good and appropriate.

Competing Interests: Statement regarding conflict. I have two connections to this research. First, Lars Chittka did a stint of postdoctoral work in my lab at Stony Brook; we collaborated on several papers in the 1990s, and co-edited a book in 2001. We correspond occasionally but have not had 
an active collaboration since then. Second, I later supervised postdoctoral research on bumble bee disease and nectar chemistry by Robert Gegear, dissertations by Michael Otterstatter and Jessamyn Manson, and undergraduate research by Miruna Draguleasa. I share authorship on several of their papers that are cited prominently by Baracchi et al.

I confirm that I have read this submission and believe that I have an appropriate level of expertise to confirm that it is of an acceptable scientific standard.

\section{Version 1}

Reviewer Report 20 April 2015

https://doi.org/10.5256/f1000research.6717.r8216

(C) 2015 Spivak M. This is an open access peer review report distributed under the terms of the Creative Commons Attribution License, which permits unrestricted use, distribution, and reproduction in any medium, provided the original work is properly cited.

\section{Marla Spivak}

Department of Entomology, University of Minnesota, St Paul, MN, USA

Determining the extent that bumble bees may self-medicate by consuming floral nectar containing antimicrobial secondary plant metabolites when infected with a pathogen is a fascinating line of study. The experiments presented are well conducted and analyzed, and I found the results not entirely surprising or contradictory.

There was a temporary effect of nicotine (when provided in sugar syrup) against Crithidia bombi in Bombus terrestris workers. This effect might have been stronger and more long lasting, and even might have cleared the infection, if the dose of nicotine consumed was higher. This could be tested in future experiments using the high- and low-end concentrations found in floral nectar. Even though the infected bees preferred sucrose laced with nicotine in the clever foraging tests and in petri dishes, the authors say the results should be interpreted with caution because the life expectancy of the infected, nicotine-fed bees was not increased relative to controls. But as they also point out, bees don't live very long, and many factors affect worker bee life expectancy. Possibly, at the colony level, reducing the infection level even for a few days in a certain number of workers might slow the rate of horizontal transmission among nest mates; this remains to be tested.

I think it would be revealing to test the effects of these alkaloids, or other plant metabolites, on infected queen bumble bees. As Crithidia is also vertically transmitted, it would be interesting to know if the vertical transmission of this parasite could be reduced if the queen ingests nectar that contains antimicrobial metabolites. It also would be interesting to know if the infected workers that collect nectar containing these compounds feed the queen with them, potentially lowering her pathogen load, which would then might allow her to produce more reproductive male and gynes. These types of experiments are more difficult, but could yield more field-relevant results. 
Yet, the experiments presented here are great first steps in understanding a new area of research on the interaction of pollinators, pathogens and plant compounds. I greatly appreciate that the authors offer a cautionary stance in interpreting their results, but I do think, given the physiological tradeoffs involved in consuming potentially toxic compounds, that small temporary effects on individual bees might translate to larger effects at the colony-level.

Competing Interests: No competing interests were disclosed.

\section{I confirm that I have read this submission and believe that I have an appropriate level of expertise to confirm that it is of an acceptable scientific standard.}

Author Response ( ) 27 May 2015

Lars Chittka, Queen Mary University of London, Mile End Road, London, UK

Referee comment: Determining the extent that bumble bees may self-medicate by consuming floral nectar containing antimicrobial secondary plant metabolites when infected with a pathogen is a fascinating line of study. The experiments presented are well conducted and analyzed, and I found the results not entirely surprising or contradictory.

Author reply: We agree both and we changed the title and the discussion accordingly.

Referee comment: There was a temporary effect of nicotine (when provided in sugar syrup) against Crithidia bombi in Bombus terrestris workers. This effect might have been stronger and more long lasting, and even might have cleared the infection, if the dose of nicotine consumed was higher. This could be tested in future experiments using the high- and lowend concentrations found in floral nectar. Even though the infected bees preferred sucrose laced with nicotine in the clever foraging tests and in petri dishes, the authors say the results should be interpreted with caution because the life expectancy of the infected, nicotine-fed bees was not increased relative to controls. But as they also point out, bees don't live very long, and many factors affect worker bee life expectancy. Possibly, at the colony level, reducing the infection level even for a few days in a certain number of workers might slow the rate of horizontal transmission among nest mates; this remains to be tested.

I think it would be revealing to test the effects of these alkaloids, or other plant metabolites, on infected queen bumble bees. As Crithidia is also vertically transmitted, it would be interesting to know if the vertical transmission of this parasite could be reduced if the queen ingests nectar that contains antimicrobial metabolites. It also would be interesting to know if the infected workers that collect nectar containing these compounds feed the queen with them, potentially lowering her pathogen load, which would then might allow her to produce more reproductive male and gynes. These types of experiments are more difficult, but could yield more field-relevant results. Yet, the experiments presented here are great first steps in understanding a new area of research on the interaction of pollinators, pathogens and plant compounds. I greatly appreciate that the authors offer a cautionary stance in interpreting their results, but I do think, given the physiological tradeoffs involved in consuming potentially toxic compounds, that small temporary effects on individual bees 
might translate to larger effects at the colony-level.

Author reply: We agree and we now explain in the discussion that our results provide potential evidence for self-medication. Yet, until measurable benefits for the bees or the colonies are found we think that caution is warranted.

Competing Interests: $\mathrm{n} / \mathrm{a}$

Reviewer Report 10 April 2015

https://doi.org/10.5256/f1000research.6717.r8215

(C) 2015 Simone-Finstrom M. This is an open access peer review report distributed under the terms of the Creative Commons Attribution License, which permits unrestricted use, distribution, and reproduction in any medium, provided the original work is properly cited.

\section{Michael Simone-Finstrom}

Department of Entomology, North Carolina State University, Raleigh, NC, USA

The authors presented a fairly comprehensive set of experiments in order to elucidate the role that nicotine may have in self-medication of bumblebees against Chrithidia infection. The experiments progress well, starting with controlled lab infection studies to lab-based diet and lifespan analysis to a semi-field foraging test. I think the authors sufficiently described the methods and subsequent results and mostly had an appropriate discussion of the relevant findings. I just have a few small issues that the authors could address to improve and clarify aspects of the manuscript. But overall it is a strong paper.

First, I do think "contradictory" could be removed from the title as I don't think the results are necessarily contradictory, but do just show a weak effect. Just because the ingestion of nicotine reduces parasite infection and does not have a subsequent effect of increasing lifespan of infected bees, this does not mean that there are no other fitness-related benefits or that at different doses effects may not be more pronounced. I think "weak effect" aptly describes the findings.

Generally, tables and figures could be labeled more effectively. For example, I think the fact that Figure 1 and 2 have the same $x$-axis is problematic given what the experimental treatments were. I think in Figure 2 it would be better to indicate that the Nicotine there is the Nicotine pre-

treatment. Same for Table 2. Whereas in Figure 1 it would be nicotine diet. The legend for Figure 3 should explicitly state that these bees were all uninfected, since this is an important point, and since the lifespan data of infected bees is not represented in a figure.

For the discussion and results, overall I think there just are a few other points that can be made. One is simply drawing stronger connections across the multitude of tests that were done.

Infection experiments: would it be valuable to show statistically that there is no difference between the pre-treated Chrithidia and the standard (basically comparing figure 1 and figure 2)? 
Also is the 2-hour exposure time relevant? How was this decided upon? Same for dose of exposure. I think this needs to be discussed more thoroughly or at least a citation provided to justify this amount.

Trade-off: Important to note that Chrithidia infection was found to reduce lifespan of bees (as compared to the bees in the toxicity part of the study).

I think a discussion of the relevance of the doses used is important. Were any dose-response trials conducted? Presumably at a higher dose, it would be even more toxic to the bees and lower doses may not have much of an effect.

Could ingestion of nectar alkaloids be a generalized response to sickness? So maybe it's not as effective against Chrithidia, but this isn't the only parasite bumblebees get.

A larger context into how this might influence colony dynamics and health is important. This is hinted at in a couple sentences, but since all of these studies were really done with individual bees or individual behavior, this is a significant point. Perhaps lifespan analysis of forager bumblebees would be different in a social setting. Similarly perhaps fitness benefits aren't seen since it's just measured in terms of individual lifespan, but maybe a reduction in parasite load affects foraging efficiency or nursing ability and thus colony productivity.

Competing Interests: No competing interests were disclosed.

\section{I confirm that I have read this submission and believe that I have an appropriate level of expertise to confirm that it is of an acceptable scientific standard.}

Author Response ( ) 27 May 2015

Lars Chittka, Queen Mary University of London, Mile End Road, London, UK

Referee comment: First, I do think "contradictory" could be removed from the title as I don't think the results are necessarily contradictory, but do just show a weak effect. Just because the ingestion of nicotine reduces parasite infection and does not have a subsequent effect of increasing lifespan of infected bees, this does not mean that there are no other fitnessrelated benefits or that at different doses effects may not be more pronounced. I think "weak effect" aptly describes the findings.

Author reply: As suggested by the referee we removed the word "Contradictory" from the title and phrased it as a question instead.

Referee comment: Generally, tables and figures could be labelled more effectively. For example, I think the fact that Figure 1 and 2 have the same $x$-axis is problematic given what the experimental treatments were. I think in Figure 2 it would be better to indicate that the Nicotine there is the Nicotine pre-treatment. Same for Table 2. Whereas in Figure 1 it would be nicotine diet.

Author reply: As suggested by the referee we labelled more effectively the figures and the tables as outlined above. 
Referee comment: For the discussion and results, overall I think there just are a few other points that can be made. One is simply drawing stronger connections across the multitude of tests that were done.

Author reply: We changed part of the discussion to address this concern.

Referee comment: Infection experiments: would it be valuable to show statistically that there is no difference between the pre-treated Crithidia and the standard (basically comparing figure 1 and figure 2)?

Author reply: As suggested by the referee we added the statistical test.

Referee comment: Also is the 2-hour exposure time relevant? How was this decided upon? Same for dose of exposure. I think this needs to be discussed more thoroughly or at least a citation provided to justify this amount.

Author reply: In the Materials and Methods section we provided a citation to justify the protocol used.

Referee comment: Trade-off: Important to note that Crithidia infection was found to reduce lifespan of bees (as compared to the bees in the toxicity part of the study).

Author reply: We stressed this point more clearly in the revised version.

Referee comment: I think a discussion of the relevance of the doses used is important. Were any dose-response trials conducted? Presumably at a higher dose, it would be even more toxic to the bees and lower doses may not have much of an effect.

Author reply: We agree and since the same point has been also raised by a second referee Uames Thomson) we discuss carefully and more clearly this important point in the revised version.

Referee comment: Could ingestion of nectar alkaloids be a generalized response to sickness? So maybe it's not as effective against Crithidia, but this isn't the only parasite bumblebees get.

Author reply: The referee suggestion is valid and we now mention this in the discussion.

Referee comment: A larger context into how this might influence colony dynamics and health is important. This is hinted at in a couple sentences, but since all of these studies were really done with individual bees or individual behavior, this is a significant point. Perhaps lifespan analysis of forager bumblebees would be different in a social setting. Similarly perhaps fitness benefits aren't seen since it's just measured in terms of individual lifespan, but maybe a reduction in parasite load affects foraging efficiency or nursing ability and thus colony productivity. 
Author reply: In line with the important comment, also raised by a second referee Uames Thomson), we added a paragraph to further discuss these issues.

Competing Interests: $\mathrm{n} / \mathrm{a}$

Reviewer Report 27 March 2015

https://doi.org/10.5256/f1000research.6717.r8036

(C) 2015 Thomson J. This is an open access peer review report distributed under the terms of the Creative Commons Attribution License, which permits unrestricted use, distribution, and reproduction in any medium, provided the original work is properly cited.

\section{James D. Thomson}

Department of Ecology and Evolutionary Biology, University of Toronto, Toronto, ON, Canada

Content of paper. This paper reports a set of nicely designed experiments aimed at determining whether Bombus terrestris self-medicates against trypanosome (Crithidia bombi) infection by seeking and consuming nicotine-laced floral nectar. Using captive bee colonies and artificial flowers in laboratory conditions permits well-controlled manipulative experiments that would be effectively impossible in the field. The results are ambivalent, in that dietary nicotine does reduce the intensity of gut infection, and infected bees do seek out nicotine, but attempts to demonstrate improved health in terms of worker bee lifespan yield negative results. For the most part, I endorse both the interpretation of these results and the recognition by Baracchi et al. that further research is needed to settle the question of self-medication.

I do have three reservations about the interpretations offered here, however, and I think the paper would be improved by some additional discussion of these issues. First, any anti-parasitic medicinal effects of toxic compounds will depend on dose rates. Too much medicine may harm the host; too little may exert no therapeutic effect. Baracchi et al. state that they have used "natural" dosages of nicotine, but what that means is that they have prepared solutions whose nicotine levels match those reported from some floral nectars. That is an appropriate starting point, but there may be little correspondence between the concentrations that flowers offer and those that bees are exposed to in a natural colony. Foraging workers typically collect floral nectar from various plant species that differ in nectar chemistry. Much of what they collect is not digested by the collectors themselves, but is transported back to the nest and regurgitated into communal honeypots that serve as energy stores for the larvae, the queen, and the many workers that do not forage. As this complicated cocktail is assembled, soluble compounds are concentrated by evaporation, diluted by mixing with other nectars, and probably further modified by enzymatic and microbial action. There is no reason to expect that the concentration of any particular compound in this brew bears any relationship to its concentration in one of the many floral nectars that have been pooled. Indeed, honeypots within a nest may hold different mixtures because particular foragers tend to discharge their collections into particular honeypots. I believe that explicit attention must be paid to honeypot composition if the question of bee medication is 
to advance.

Second, by choosing to look at toxic effects on workers, Baracchi et al. are not able to detect possible benefits of medication on other members of the colony, specifically larvae or the queen. One can imagine that certain inputs of nicotine to the colony might have no net effects of worker survival but might allow the queen to lay more eggs or the larvae to prosper. Indeed, effects could conceivably be harmful for the foragers but still beneficial to the colony. There might also be different effects on workers that forage and those that serve as nurses. The social nature of these bees must be considered.

Third, by considering nectar only, Baracchi et al. don't consider the probability that secondary metabolites found in nectar are also likely to occur in the pollen of the same flower species. In nature, therefore, bees that choose to forage on nicotine-rich nectars are also likely to be collecting nicotine rich pollen from those flowers. To the extent that such correlations hold in nature, the larvae (who are the primary consumers of that pollen) may be receiving very different doses than adult bees.

In summary, it would be very illuminating, although tedious, to consider experiments that measure whole-colony health as a response variable rather than worker longevity.

Errors. In this review process, the lack of line numbers, or an editable form of the MS, makes it hard to flag such things as unclear phrases. Here are a few mistakes that should be addressed, however:

In the abstract, the plant family Solanaceae is misspelled.

In the caption for Figure 1, "bees received" should be rephrased.

I believe that there must be a serious error in Dataset 2. Unless I am missing something, the data reported for "starved" and "ad libitum" treatments are identical. This looks like a cut-and-paste error.

Column headings in the tables and data sets should be more explanatory. For example, in Table 2, experimental treatments are denoted simply as "time" and "nicotine." Those labels are too cryptic. The "Statistical Analysis" section refers to several "classical...parameters," but these are not picked up in the Results. Reconcile?

Competing Interests: Statement regarding conflict. I have two connections to this research. First, Lars Chittka did a stint of postdoctoral work in my lab at Stony Brook; we collaborated on several papers in the 1990s, and co-edited a book in 2001. We correspond occasionally but have not had an active collaboration since then. Second, I later supervised postdoctoral research on bumble bee disease and nectar chemistry by Robert Gegear, dissertations by Michael Otterstatter and Jessamyn Manson, and undergraduate research by Miruna Draguleasa. I share authorship on several of their papers that are cited prominently by Baracchi et al.

I confirm that I have read this submission and believe that I have an appropriate level of expertise to confirm that it is of an acceptable scientific standard, however I have significant reservations, as outlined above. 
Author Response ( ) 27 May 2015

Lars Chittka, Queen Mary University of London, Mile End Road, London, UK

Referee comment: ...Any anti-parasitic medicinal effects of toxic compounds will depend on dose rates. Too much medicine may harm the host; too little may exert no therapeutic effect. Baracchi et al. state that they have used "natural" dosages of nicotine, but what that means is that they have prepared solutions whose nicotine levels match those reported from some floral nectars. That is an appropriate starting point, but there may be little correspondence between the concentrations that flowers offer and those that bees are exposed to in a natural colony. Foraging workers typically collect floral nectar from various plant species that differ in nectar chemistry. Much of what they collect is not digested by the collectors themselves, but is transported back to the nest and regurgitated into communal honeypots that serve as energy stores for the larvae, the queen, and the many workers that do not forage. As this complicated cocktail is assembled, soluble compounds are concentrated by evaporation, diluted by mixing with other nectars, and probably further modified by enzymatic and microbial action. There is no reason to expect that the concentration of any particular compound in this brew bears any relationship to its concentration in one of the many floral nectars that have been pooled. Indeed, honeypots within a nest may hold different mixtures because particular foragers tend to discharge their collections into particular honeypots. I believe that explicit attention must be paid to honeypot composition if the question of bee medication is to advance.

Author reply: We added a paragraph in the discussion section to address this point.

Referee comment: By choosing to look at toxic effects on workers, Baracchi et al. are not able to detect possible benefits of medication on other members of the colony, specifically larvae or the queen. One can imagine that certain inputs of nicotine to the colony might have no net effects of worker survival but might allow the queen to lay more eggs or the larvae to prosper. Indeed, effects could conceivably be harmful for the foragers but still beneficial to the colony. There might also be different effects on workers that forage and those that serve as nurses. The social nature of these bees must be considered.

Author reply: We agree and we stressed more clearly in the revised version that benefits from the consumption of nicotine may influence colony health and dynamics despite the lack of evident benefits for infected foragers.

Referee comment: By considering nectar only, Baracchi et al. don't consider the probability that secondary metabolites found in nectar are also likely to occur in the pollen of the same flower species. In nature, therefore, bees that choose to forage on nicotine-rich nectars are also likely to be collecting nicotine rich pollen from those flowers. To the extent that such correlations hold in nature, the larvae may be receiving very different doses than adult bees.

Author reply: The argument raised by the referee is valid, and we briefly mentioned this possibility 
in the discussion

Referee comment: In summary, it would be very illuminating, although tedious, to consider experiments that measure whole-colony health as a response variable rather than worker longevity.

Author reply: We feel that considering a new set of experiments to measure whole-colony health would represent not simply an additional big experiment, but a new study itself. Instead, we now carefully discuss all these issues.

Referee comment: In the abstract, the plant family Solanaceae is misspelled. In the caption for Figure 1, "bees received" should be rephrased. I believe that there must be a serious error in Dataset 2. Unless I am missing something, the data reported for "starved" and "ad libitum" treatments are identical. This looks like a cut-and-paste error.

Author reply: Thank you for spotting these errors. In the revised version we have fixed them.

Referee comment: Column headings in the tables and data sets should be more explanatory. For example, in Table 2, experimental treatments are denoted simply as "time" and "nicotine." Those labels are too cryptic.

Author reply: As suggested by the referee we labelled more effectively the figures and the date sets

Referee comment: The "Statistical Analysis" section refers to several "classical...parameters," but these are not picked up in the Results. Reconcile?

Author reply: In the revised version we have made sure that the Results section addressed all the parameters mentioned in the Methods section.

Competing Interests: $\mathrm{n} / \mathrm{a}$ 
The benefits of publishing with F1000Research:

- Your article is published within days, with no editorial bias

- You can publish traditional articles, null/negative results, case reports, data notes and more

- The peer review process is transparent and collaborative

- Your article is indexed in PubMed after passing peer review

- Dedicated customer support at every stage

For pre-submission enquiries, contact research@f1000.com 